\title{
Computational Fluid Dynamics Simulations of Gas-liquid Two-phase Flow Characteristics through a Vertical to Horizontal Right Angled Elbow
}

\author{
N. Z. AUNG ${ }^{1 *}$ AND T. YUWONO²
}

\begin{abstract}
Having a clear understanding on the phase distribution of gas-liquid two-phase flow through elbow bends is vital in mixing and separation system designs. This paper presents the computational fluid dynamics (CFD) simulations and experimental observations of gas-liquid two-phase flow pattern characteristic through a vertical to horizontal right angled $\left(90^{\circ}\right)$ elbow. Experimental observations were conducted in a transparent test section that consisted of a vertical pipe, elbow bend and horizontal pipe with an inside diameter of $0.036 \mathrm{~m}$. The CFD simulations were performed by using a computer software package, FLUENT 6.2. Bubbly flow conditions were created in the vertical test section with the variation of superficial liquid Reynolds number from 13497 to 49488 and volumetric gas quality from 0.05 to 0.2 . The CFD results showed a good agreement with experimental results in the following observations. The results showed that gas-liquid flow pattern inside and downstream of the elbow bend mainly depended on liquid velocity and it is also influenced by gas quality at high liquid velocities. At lower liquid velocities, gas-liquid separation began early in the elbow bend and gas-phase migrated to outer bend. Then, it smoothly transformed to stratified flow at elbow outlet. When the liquid velocity was further increased, the liquid phase occupied the outer bend rubbing the gas phase to the inner bend and delayed the formation of gas layer in the horizontal pipe. The increase of gas quality in higher liquid velocities promoted gas core formation at the elbow exit and caused wavy gas layers at the downstream of the elbow.
\end{abstract}

Key words: Gas-liquid; two-phase; flow pattern characteristic; vertical to horizontal; $90^{\circ}$ elbow

The understanding of transport phenomena in multiphase flows plays a vital role in improving the performance of operating systems in boiling and condensing processes, hydrocarbon production and refining, minerals transport as well as power generation. Such transport phenomena are quite sensitive to the phase distribution in the flow termed as 'flow pattern'. In turn, the flow pattern also mainly depends on the flow velocity and physical properties of each phase and pipe geometry (Akilli et al. 2001) In the case of pipe geometry, the correct usage of pipe bends is very critical in multi-phase flow piping system designs, since these can give strongly interference in phase distribution and consequently promote the vibration of the system (Abdulkadir et al. 2001) Hence, increasingly, attempts are being made to observe the effect of pipe bends (especially $90^{\circ}$ elbows) on phase distribution and other flow related characteristics in multiphase flows.

Akilli (2001) conducted experimental measurements and CFD simulations of gassolid concentration and velocity profile in horizontal pipe after vertical-to-horizontal $90^{\circ}$

\footnotetext{
${ }^{1}$ Department of Mechanical Engineering, Mandalay Technology University, Myanmar

${ }^{2}$ Laboratory of Fluid Mechanics, Department of Mechanical Engineering, Institute Technology Sepuluh Nopember, Campus ITS, Sukolilo, Surabaya

*Corresponding author (e-mail: nay1572@gmail.com; triyogi@me.its.ac.id)
} 
elbow bend. His distinct observation was that a strong rope was formed in the elbow bend and it disintegrated within $10 D$ of the pipe after elbow exit. Huseyin (2004) has also performed investigations on gas-solid flow characteristics after a $90^{\circ}$ vertical-to-horizontal elbow.

Yang and Kuan (2006) have measured the velocity fluctuation level of gas-solid flow inside a $90^{\circ}$ elbow by using Laser Doppler Anemometer (LDA). They found that the level of velocity fluctuations in the solid phase was higher than that of the gas phase at the bend entrance because of particle-wall collisions. Kim et al. (2007) investigated the effect of $90^{\circ}$ elbow on local void fraction distribution. According to their results, the elbow had more significant effect on phase distribution at further downstream $(L / D=43.9$ after elbow $)$ than immediate downstream $(L / D=18.1$ after elbow). At the same time, Spedding and Benard (2007) performed pressured drop measurements through a vertical to horizontal $90^{\circ}$ elbow bend. They proposed a general correlation for prediction of gas-liquid two-phase pressure drop for elbow bends. The same authors (2008) also reported the pressure drop characteristics of water-oil-air three-phase flow through a vertical to horizontal $90^{\circ}$ elbow bend. Concerning the air-water two-phase flow pressure drop in vertical to horizontal internal wavy $90^{\circ}$ elbow bends, Benbella et al. (2009) carried out a research. Their results demonstrated that wavy $90^{\circ}$ wavy elbows had total pressure about 2-5 times greater than smooth bends. In the work of Abdulkadir et al. (2011), the effect of $90^{\circ}$ bends on air-oil (silicon) flow pattern were observed using advanced instruments such as Electrical Capacitance Tomography (ECT), Wire Mesh Sensor Tomography (WMS) and high-speed video. Changing the flow velocities, they had discovered transitions of flow pattern before and after elbow bends. They concluded that horizontal bend has less effect on the flow patterns compared with the vertical bend.
Zhang et al. (2012) performed CFD simulations to observe erosive ware damages (puncture point locations) in elbow bends by varying slurry velocity, bend orientation and bend angle. They discovered that the location of the maximum erosive location moved to downstream (elbow exit) when slurry velocity increased. Liu et al. (2012) also experimentally studied air-water flow induced fluctuating force on a $90^{\circ}$ elbow. They discussed force fluctuation phenomenon matching with the observations of flow pattern such as bubbly flow, slug flow and churn flow. For forgoing review, a summary of information of previous researches that focused on $90^{\circ}$ elbow bend is shown in Table 1.

From the entire review, it is very obvious that multiphase flow phenomena before, inside and after elbow bend are very violent and the effects are undesirable. However, the existence of bended pipes is very common in conveying process of oil and gas mixture from downhole to separator because they are absolutely necessary for flow directional changes. Thus, in designing such bended pipes, a clear understanding of phase distribution (or flow pattern) before, inside and after the bend is very critical since these can negatively affect the performance of operating system.

However, available information in literature is mostly based on probe measurement. Indeed, experiences in visual observations of multiphase flow phenomena without any intrusive measuring tool are still lack and needed to obtain a better understanding on the phase distribution through bended pipes. Even though some visual observations can be found in Abdulkadir (2011), the focus point was only inside the elbow bend. Without having visual information at the downstream of the elbow bend, a sharp imagination still cannot be made in designing a bend pipe. Moreover, long elbow bends are also becoming attractive in industrial applications and related information is in demand. 
Table 1. Summary of previous researches that focused on effect of elbow.

\begin{tabular}{|c|c|c|c|}
\hline Research (Reference no.) & $\begin{array}{l}\text { Multiple-phase } \\
\text { classification }\end{array}$ & Elbow geometry & Methodology \\
\hline Huseyin et al. 2004 & $\begin{array}{l}\text { Gas-solid } \\
\text { (Two-phase) }\end{array}$ & $\begin{array}{l}\mathrm{R} / \mathrm{D}=1.5,3 \text { (vertical to } \\
\text { horizontal upward flow) }\end{array}$ & $\begin{array}{l}\text { Experiment, CFD } \\
\text { simulation }\end{array}$ \\
\hline Kim et al. 2007 & $\begin{array}{l}\text { Gas-solid } \\
\text { (Two-phase) }\end{array}$ & $\begin{array}{l}\mathrm{R} / \mathrm{D}=1.5,3 \text { (vertical to } \\
\text { horizontal upward flow) }\end{array}$ & Experiment \\
\hline Liu at al. 2012 & $\begin{array}{l}\text { Gas-solid } \\
\text { (Two-phase) }\end{array}$ & $\begin{array}{l}\mathrm{R} / \mathrm{D}=1.5 \text { (horizontal to vertical } \\
\text { upward flow }\end{array}$ & Experiment \\
\hline Mahvash \& Ross 2008 & $\begin{array}{l}\text { Gas-liquid } \\
\text { (Two-phase) }\end{array}$ & $\begin{array}{l}\mathrm{R} / \mathrm{D}=1.515 \text { (horizontal to } \\
\text { horizontal, the same plane flow) }\end{array}$ & Experiment \\
\hline Mahmoud et al. 2012 & $\begin{array}{l}\text { Gas-liquid } \\
\text { (Two-phase) }\end{array}$ & $\begin{array}{l}\mathrm{R} / \mathrm{D}=0.654 \text { (vertical to } \\
\text { horizontal upward flow }\end{array}$ & Experiment \\
\hline Margot et al. 2012 & $\begin{array}{l}\text { Gas-liquid-liquid } \\
\text { (Three-phase) }\end{array}$ & $\begin{array}{l}\mathrm{R} / \mathrm{D}=0.654 \text { (vertical to } \\
\text { horizontal upward flow }\end{array}$ & Experiment \\
\hline Riverina et al. 2006 & $\begin{array}{l}\text { Gas-liquid } \\
\text { (Two-phase) }\end{array}$ & $\begin{array}{l}\mathrm{R} / \mathrm{D}=4,6,8,10 \text { (vertical to } \\
\text { horizontal upward flow }\end{array}$ & $\begin{array}{l}\text { Experiment and } \\
\text { correlations }\end{array}$ \\
\hline Singhal et al. 2002 & $\begin{array}{l}\text { Gas-liquid } \\
\text { (Two-phase) }\end{array}$ & $\begin{array}{l}\mathrm{R} / \mathrm{D}=2.3 \text { (vertical to } \\
\text { horizontal upward flow) }\end{array}$ & Experiment \\
\hline Spedding \& Benard 2007 & $\begin{array}{l}\text { Gas-solid } \\
\text { (Two-phase) }\end{array}$ & $\begin{array}{l}\mathrm{R} / \mathrm{D}=3.255 \text { (various } \\
\text { orientations) }\end{array}$ & CFD simulation \\
\hline Spedding et al. 2008 & $\begin{array}{l}\text { Gas-liquid } \\
\text { (Two-phase) }\end{array}$ & $\begin{array}{l}\mathrm{R} / \mathrm{D}=1.451 \text { (vertical to } \\
\text { horizontal upward flow) }\end{array}$ & Experiment \\
\hline
\end{tabular}

In this regard, the aim of this work is to experimentally and numerically observe phase distribution (the flow pattern) characteristic of gas-liquid two-phase bubbly flow through a vertical to horizontal right angled $\left(90^{\circ}\right)$ long elbow bend with a wide focusing view and to provide more descriptive information.

\section{NUMERICAL SIMULATION}

Advanced computational methods in fluid dynamics are becoming powerful and capable of modeling multiphase flows and the acceptable simulated results are at proven stage in many researches (Akilli 2001; Zhang 2012; Singhal 2002). Thus, the CFD simulations of gas-liquid two-phase flow through a vertical to horizontal elbow bend are also performed to confirm the experimental observations in this work.

\section{Governing Equations}

Flow governing equations for a two-phase mixture are obtained from the ensemble averaging of the Navier-Stokes equations and the following mass and momentum continuity equations are solved in computation.

\section{Continuity equation:}

$$
\frac{\partial\left(\rho_{m}\right)}{\partial t}+\nabla \cdot\left(\rho_{m} \vec{u}_{m}\right)=0
$$

Momentum transfer equation:

$$
\begin{aligned}
& \frac{\partial\left(\rho_{m} \varepsilon\right)}{\partial t}+\nabla \cdot\left(\rho_{m} \vec{u}_{m} \vec{u}_{m}\right)= \\
& -\nabla p+\nabla \cdot\left[\mu_{m}\left(\nabla \vec{u}_{m}+\vec{u}_{m}^{T}\right)\right]+\rho_{m} \vec{g}+ \\
& \vec{F}+\nabla \cdot\left(\sum_{k=1}^{n} \alpha_{k} \rho_{k} \vec{u}_{d r, k} \vec{u}_{d r, k}\right)
\end{aligned}
$$


where, the subscript $m, k, d r$ describe the mixture, secondary phase and drift respectively, $\rho$ is density, $t$ is time, $\mu$ is viscosity, $\vec{u}$ is velocity, $p$ is pressure, $\vec{F}$ is body force vector, $\alpha$ is volume fraction.

For having reasonable accuracy (Singhal 2002; Margot 2002; Mahmoud 2012) the standard $k$ - $\varepsilon$ model is adopted to solve the set of turbulent kinetic energy and dissipation rate equations. The equations for mixture turbulent kinetic energy and its dissipation rate are obtained by the summation of mixture as a single phase.

Turbulent kinetic energy equation:

$$
\begin{gathered}
\frac{\partial\left(\rho_{m} k\right)}{\partial t}+\nabla \cdot\left(\rho_{m} \vec{u}_{m} k\right)=\nabla \cdot\left(\frac{\mu_{t, m}}{\sigma_{k}} \nabla k\right)+ \\
G_{k, m}-\rho_{m} \varepsilon
\end{gathered}
$$

Turbulent dissipation equation:

$$
\begin{aligned}
& \frac{\partial\left(\rho_{m} \varepsilon\right)}{\partial t}+\nabla \cdot\left(\rho_{m} \vec{u}_{m} \varepsilon\right)=\nabla \cdot\left(\frac{\mu_{t, m}}{\sigma_{k}} \nabla \varepsilon\right)+ \\
& \quad \frac{\varepsilon}{k}\left(C_{1 \varepsilon} G_{k, m}-C_{2 \varepsilon} \rho_{m} \varepsilon\right)
\end{aligned}
$$

The turbulent viscosity of the mixture was calculated by:

$$
\mu_{t, m}=C_{\mu} \rho_{m} \frac{k^{2}}{\epsilon}
$$

where the subscript $t$ represents for turbulent, $k$ is turbulent kinetic energy, $\varepsilon$ is turbulent dissipation rate, $C_{1 \varepsilon}, C_{2 \varepsilon}, C_{\mu}, \sigma_{k}$ and $\sigma_{\varepsilon}$ are the standard $k-\varepsilon$ model constants and $G$ is the turbulence production term. This standard model is used without any further modifications taking $C_{1 \varepsilon}=1.44, C_{2 \varepsilon}=1.92, C_{\mu}=0.09, \sigma_{k}=1$ and $\sigma_{\varepsilon}=1.3$ since they have been accepted in a wide range of wall-bounded air and water turbulent flows.

\section{Computational Domain}

The whole test section is considered as the computational domain and constructed in GAMBIT 2.2. It is shown in Figure $3 a-3 b$.
The mesh has 240000 hexahedral elements. The base of vertical pipe is set as velocity inlet condition and the end of horizontal as outflow condition. No slip condition is considered at the walls.

\section{Solving Strategies}

A commercial CFD package FLUENT 6.2 is used to solve the set of governing equations; continuity, momentum, and turbulent $k-\varepsilon$ equations. Velocities of phases and gas phase fraction are set as known inlet boundary condition for every run. The SIMPLEC algorithm is used for coupling between velocity and pressure. The second-order upwind discretization scheme is used for the momentum equations while first-order upwind discretization is used for volume fraction and $k-\varepsilon$ equations. The convergence criteria are third order residual value of each parameter and deviation of $10^{-5}$ between the inlet and outlet mass flow rates to satisfy the continuity law.

\section{EXPERIMENTAL SETUP AND PROCEDURE}

The schematic diagram of constructed air-water two-phase flow loop is shown in Figure 1. The test section consists of $2.1 \mathrm{~m}$ long vertical pipe, elbow bend and a horizontal pipe that runs $1 \mathrm{~m}$ after the elbow exit. The vertical and horizontal pipes are acrylic pipes which have inside diameter of $0.036 \mathrm{~m}$. The elbow bend is also made of acrylic material and has the same inside diameter. The detail structure of the elbow bend is shown in Figure 2. Aiming to create bubbly flow in vertical test section, the air is injected at the base of vertical test section by using radial injectors. There are 32 ports of $710 \mu \mathrm{m}$ diameter along the periphery of the injector. The liquid flow rate is measured by using "Doppler" flow meter and the gas flow rate is measured by using float type (Dwyer Rate-Master) gas flow meter. Two high speed digital cameras are used to capture the visual observation of flow patterns in vertical pipe, inside elbow bend and at its downstream. Experiments are conducted 


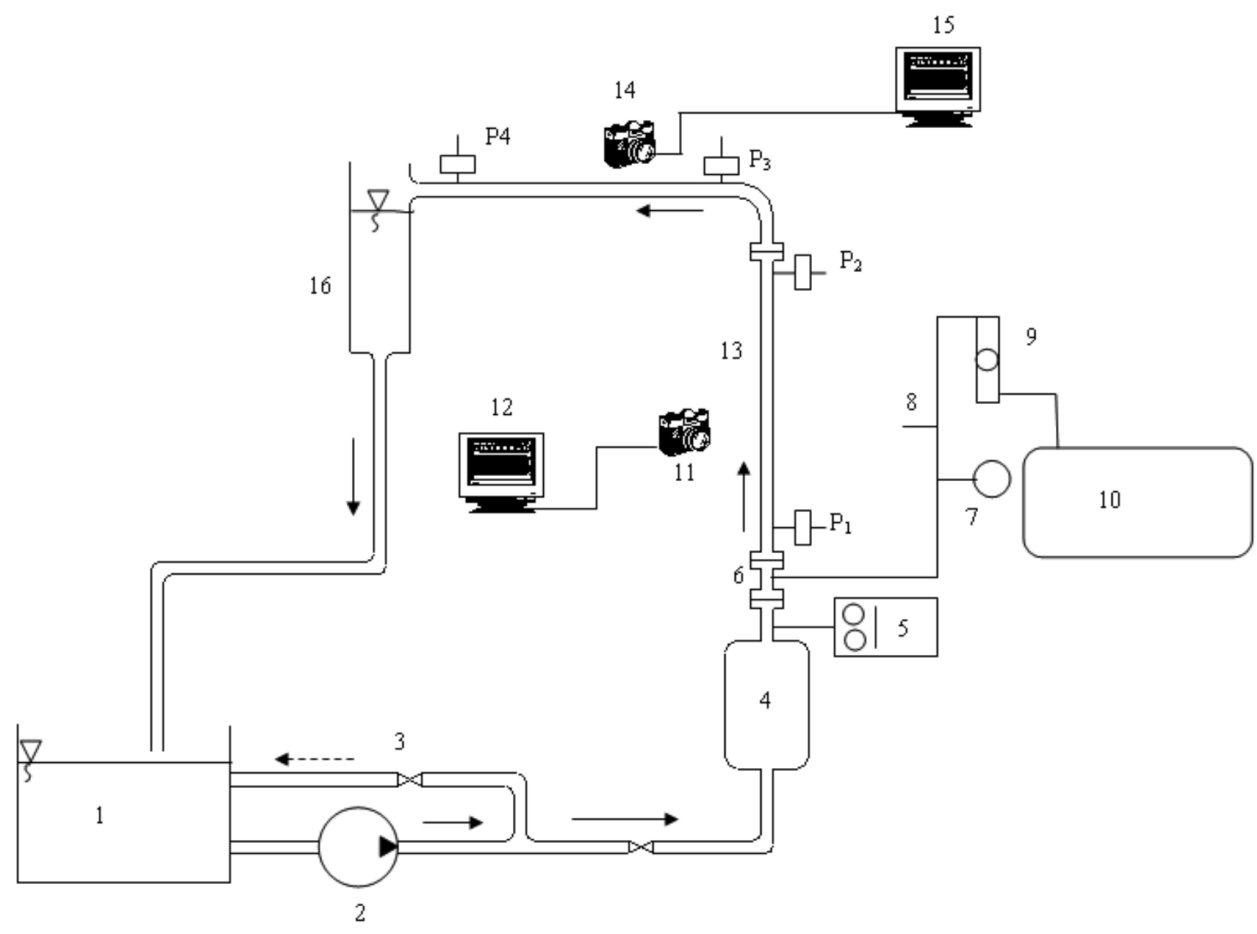

1. Water tank

2. Pump

3. Regulation system (Bypass)

4. Accumulator

5. Doppler flow meter
6. Annular air injector

7. Pressure gauge

8. Thermocouple

9. Rotameter

10. Compressor
11. Digital camera 1

12. Photo editing system 1

13. Test section

14. Digital camera 2

15. Photo editing system 2

16. Gas-liquid separator

Figure 1. Schematic diagram of experimental test loop.

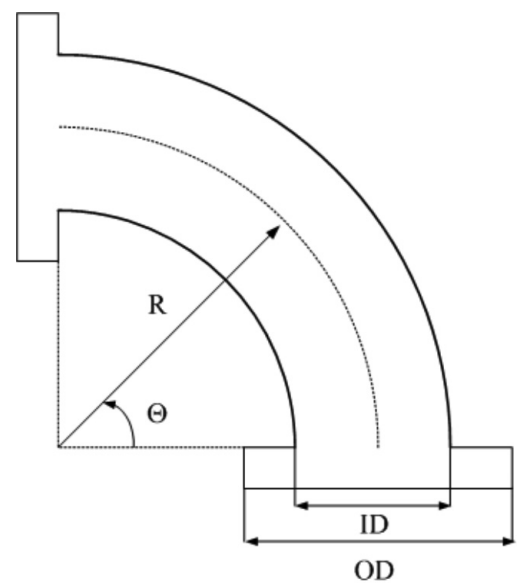

Curvature radius, $\mathrm{R}=0.09 \mathrm{~m}$

Inside diameter, ID $=0.036 \mathrm{~m}$

Outside diameter, ID $=0.04 \mathrm{~m}$

Figure 2. Detail structure of elbow bend. 


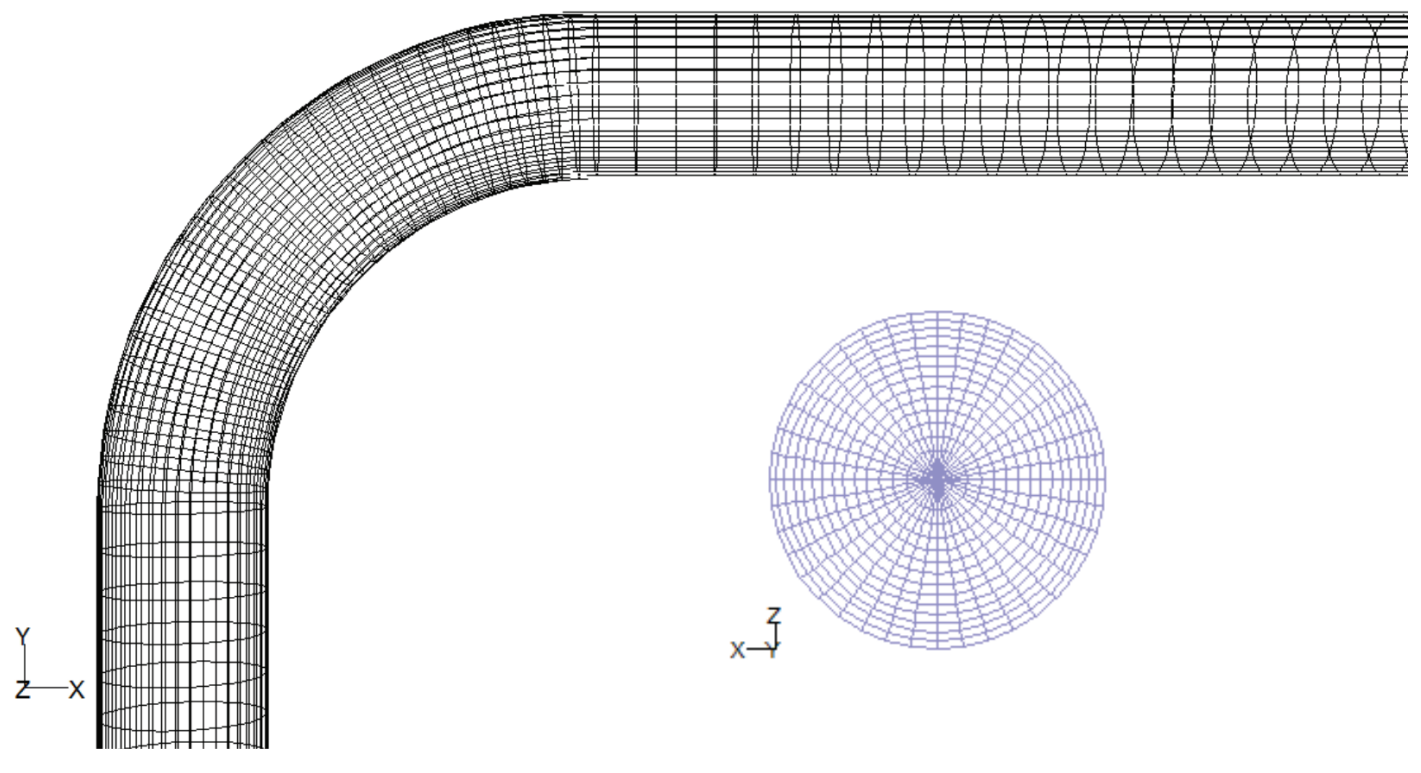

(a)

(b)

Figure 3. Computational grid structure of test section: (a) Side view ( $x$-y plane) (b) Cross-sectional view ( $x-z$ plane and $y$-z plane).

by varying superficial liquid velocity and volumetric gas quality. The liquid superficial velocity (in terms of Reynolds number) is varied in the range of $R e_{S L}=13497$ to 49488 and the gas volumetric quality $(\beta)$ is varied in the range of $0.05-0.2$. These initial parameters are calculated from measureable parameters by using equations expressed in Appendix.

\section{RESULTS AND DISCUSSION}

\section{Flow Pattern in Vertical Test Section}

In this work, for all flow conditions, bubbly flow regimes are created in the vertical test section at the upstream of elbow bend. The visual observations of bubbly flow are captured with a high speed digital camera at a height of $0.35 \mathrm{~m}$ above the air injector. Some sample observations of the bubbly flows in vertical test section are shown in Figures $4 a-4 c$. The observed bubbly flows can be classified into three categories.
Clustered bubbly flow. This kind of flow occurs at high superficial liquid velocities $\left(R e_{S L}=40490, R e_{S L}=49488\right)$ with low volumetric gas qualities $(\beta=0.05, \beta=0.07)$ as shown in Figure $4 a$. The gas phase (bubbles) are cluttered in liquid medium forming bubbleclusters. In other word, the bubble distribution is not symmetric to the vertical axis of the pipe at any elevation and a series of bubble-clusters is formed along the pipe.

Homogeneous bubbly flow. This flow condition is observed at every flow condition with medium range of volumetric gas qualities $(\beta=0.09-0.13)$ as shown in Figure $4 b$. The bubble size becomes larger and it seems that the bubbles occupy homogeneously over the entire cross-section of the pipe at any elevation.

Dense bubbly flow. Figure $4 c$ shows dense bubbly flow condition. It is clear that this kind of bubbly flow occurs at high gas qualities. 


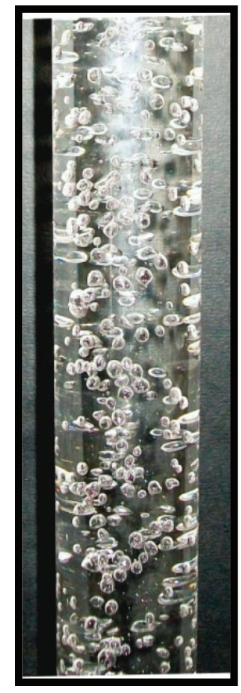

(a)

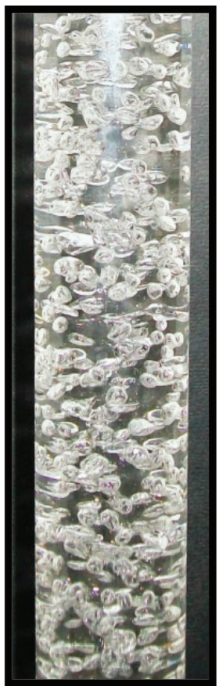

(b)

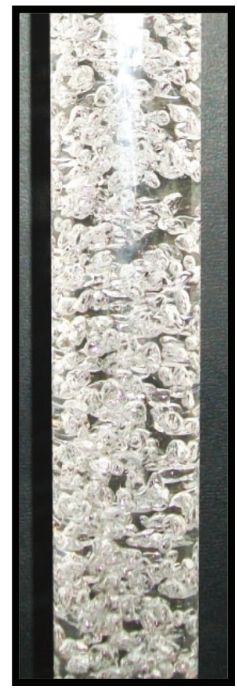

(c)

Figure 4. Visual observations of bubbly flow in vertical test section: (a) $\operatorname{Re}_{\mathrm{SL}}=49488 ; \beta=0.05$; (b) $\operatorname{Re}_{\mathrm{SL}}=31492 ; \beta=0.11 ;$; ( ) $\operatorname{Re}_{\mathrm{SL}}=40490 ; \beta=0.2$.

The entire cross sectional area of the pipe is filled with bubbles, but formation of elongated bubbles is not yet observed.

\section{Flow Pattern in Elbow Bend and Downstream}

Figures 5-9 show the experimental observations and numerically simulated results of gas-liquid two-phase flow patterns through the elbow bend for flow conditions of $R_{S L}=13497-49488$ with constant volumetric gas quality $\beta=0.2$. The numerical results are taken from both longitudinal mid-plane and transverse crosssectional plane at various distances inside and after elbow bend. The experimental results clearly state that the two-phase flow pattern is mainly governed by liquid velocity. For flow conditions with low liquid velocities (Figures $5-6)$, the gas phase starts to separate from inner wall about bend angle $(\Theta)$ of $30^{\circ}-45^{\circ}$ and flows up to the outer wall. It can be explained that the momentum and buoyancy force attained by bubbles overcomes the pressure at the outer surface of the elbow and the bubbles try to migrate to the outer surface. Then, gas-liquid stratification begins before the exit of the elbow bend. Further increase of liquid velocity $\left(R e_{S L}=31492\right)$ delays the gas phase separation from inner surface of elbow bend showing uniformly distribution in the elbow bend. At the outlet of elbow bend, the gas phase moves up to upper surface of horizontal pipe. Formation of gas layer initiates about 2D-3D after elbow exit. Figures $8-9$ depict comparisons of recorded and computed results for flow conditions of $R e_{S L}=40490$ and $R e_{S L}=49488$ with constant gas quality. In contrast to the former observations, the gas phase leaves away from the outer surface of the elbow and totally concentrates on inner bend. The whole outer surface of the elbow bend is free from migration of gas bubbles and the entire inner surface is apparently covered by gas layer. This phenomenon is related to the increasing of pressure at the outer bend. When the mixture enters into the elbow bend with a high velocity, the liquid phase with higher 


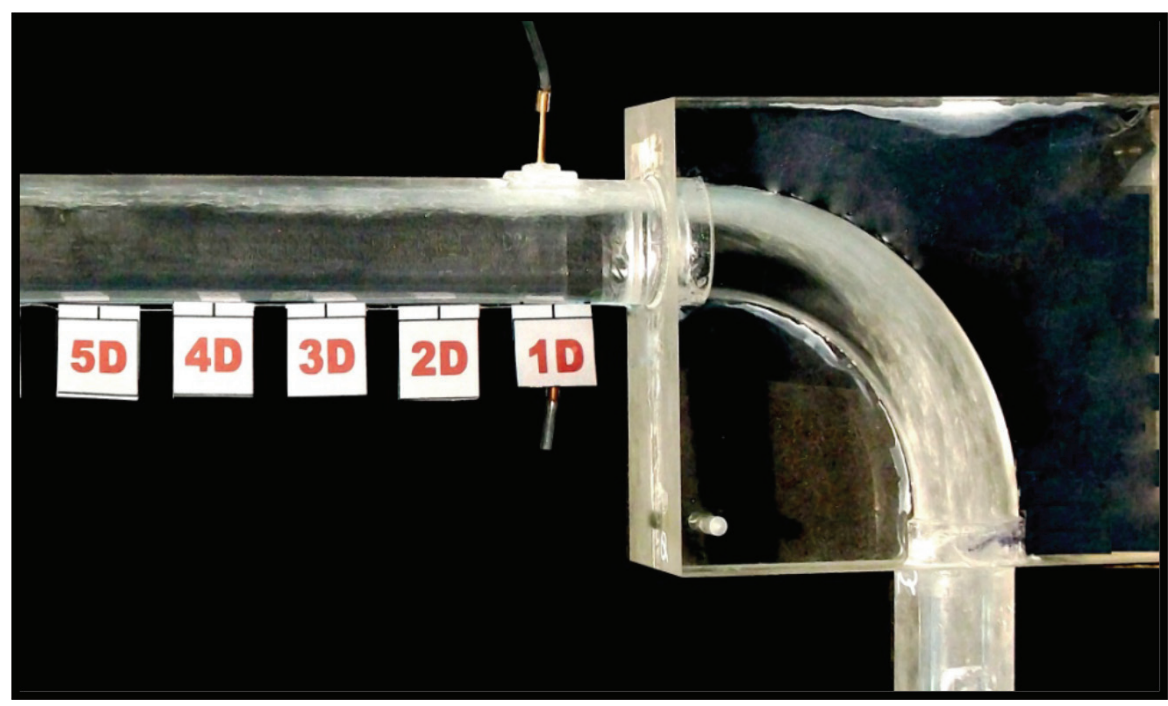

(a)

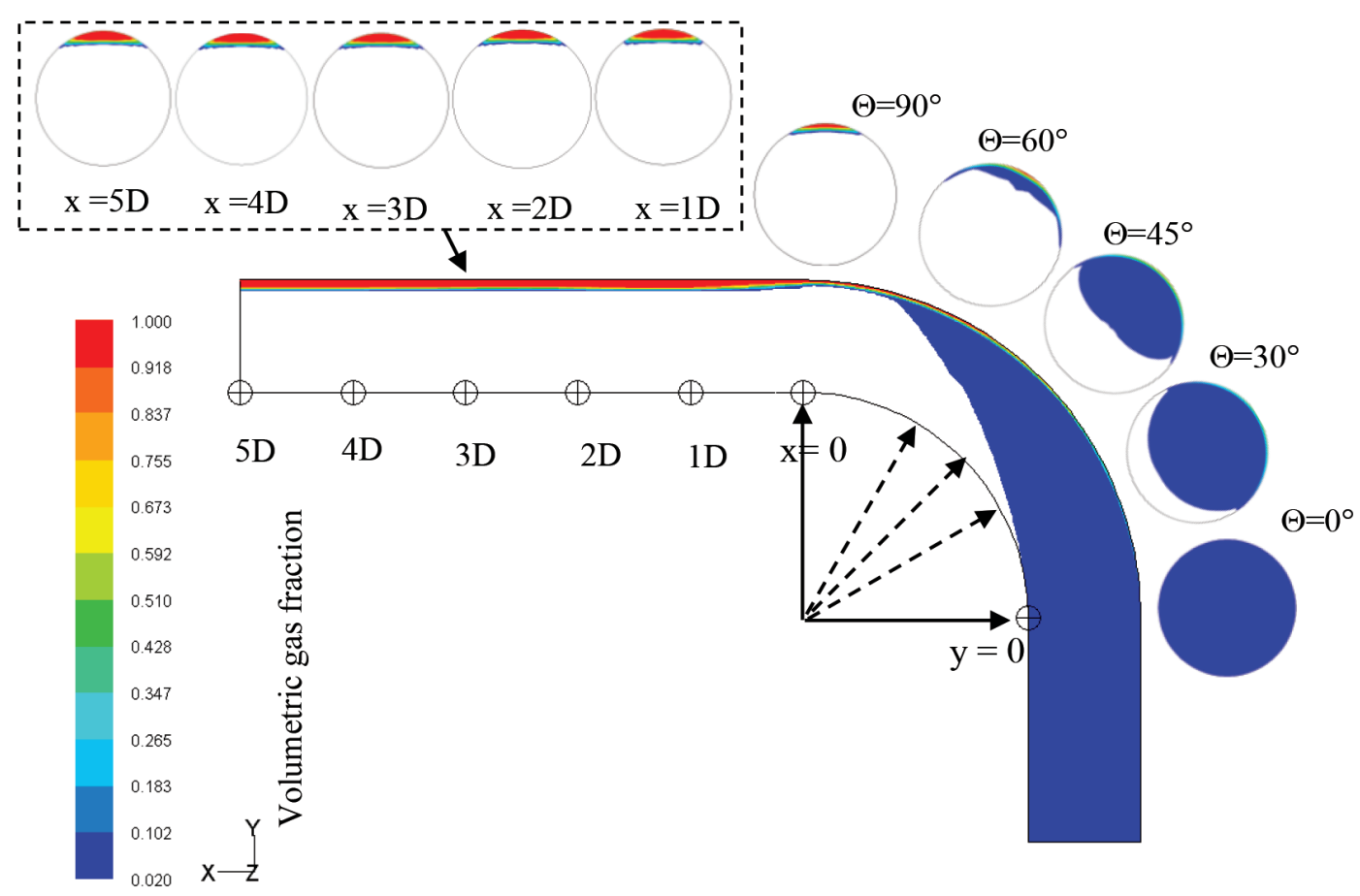

(b)

Figure $5(a)-(b)$. Experimental and numerical observation of two-phase flow pattern through elbow bend at $\mathrm{Re}_{\mathrm{SL}}=13497, \beta=0.2$. 


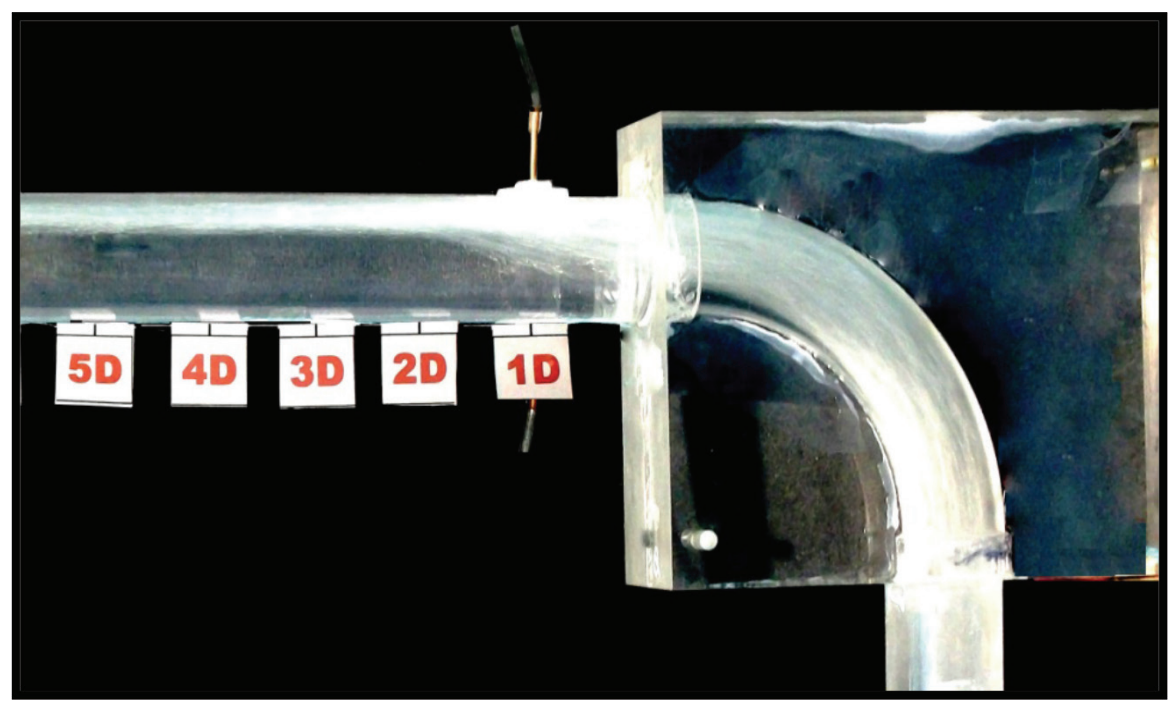

(a)

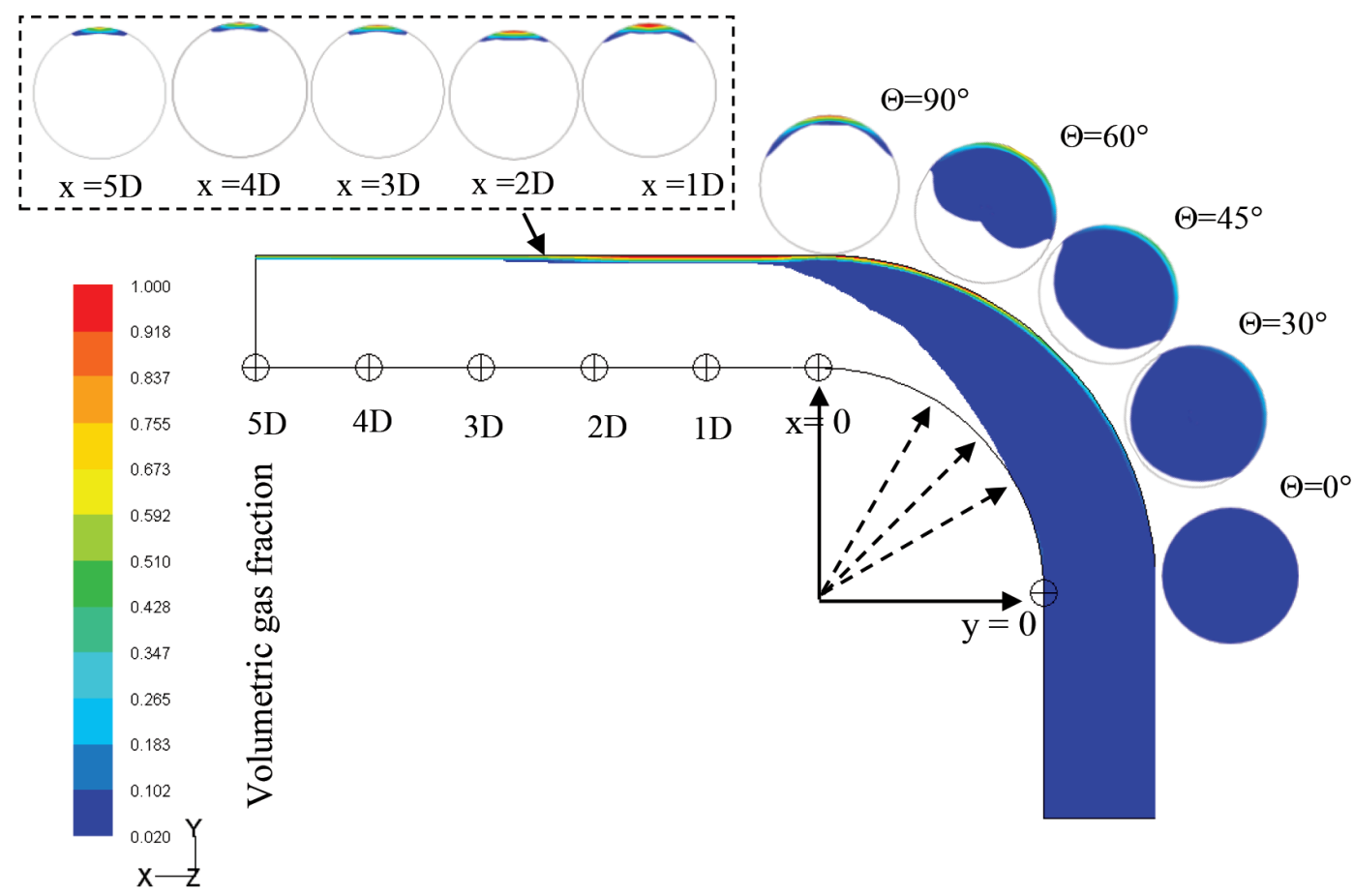

(b)

Figure $6(a)-(b)$. Experimental and numerical observation of two-phase flow pattern through elbow bend at $\mathrm{Re}_{\mathrm{SL}}=22494, \beta=0.2$. 


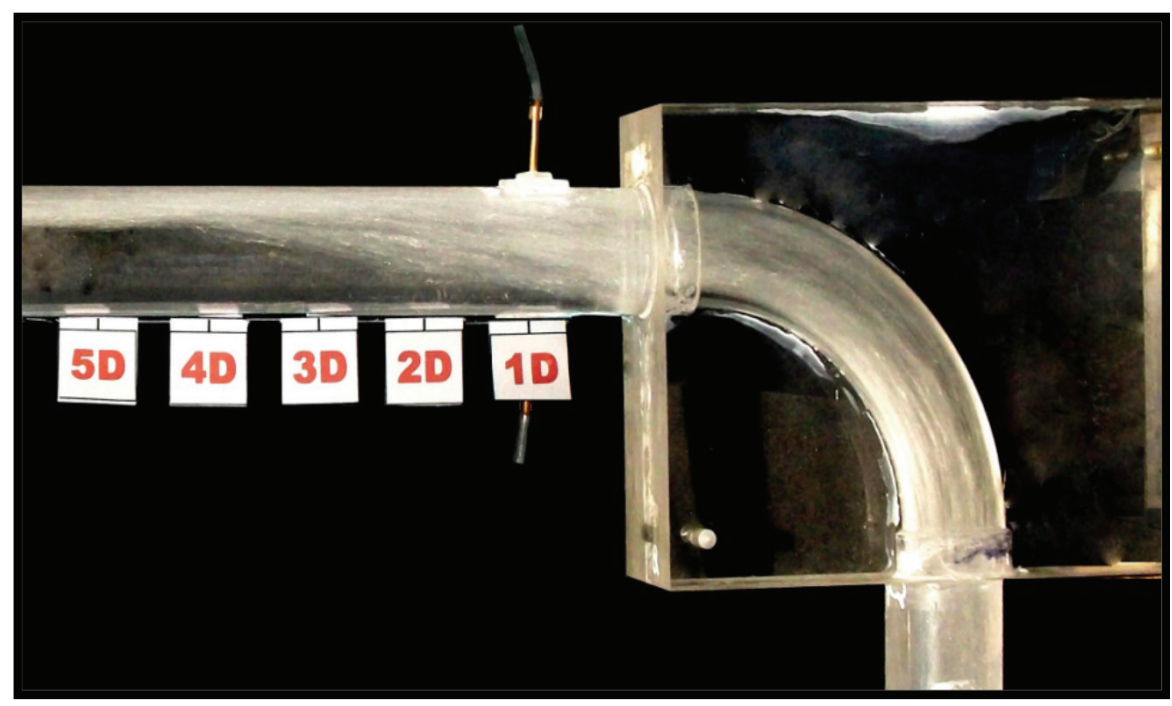

(a)

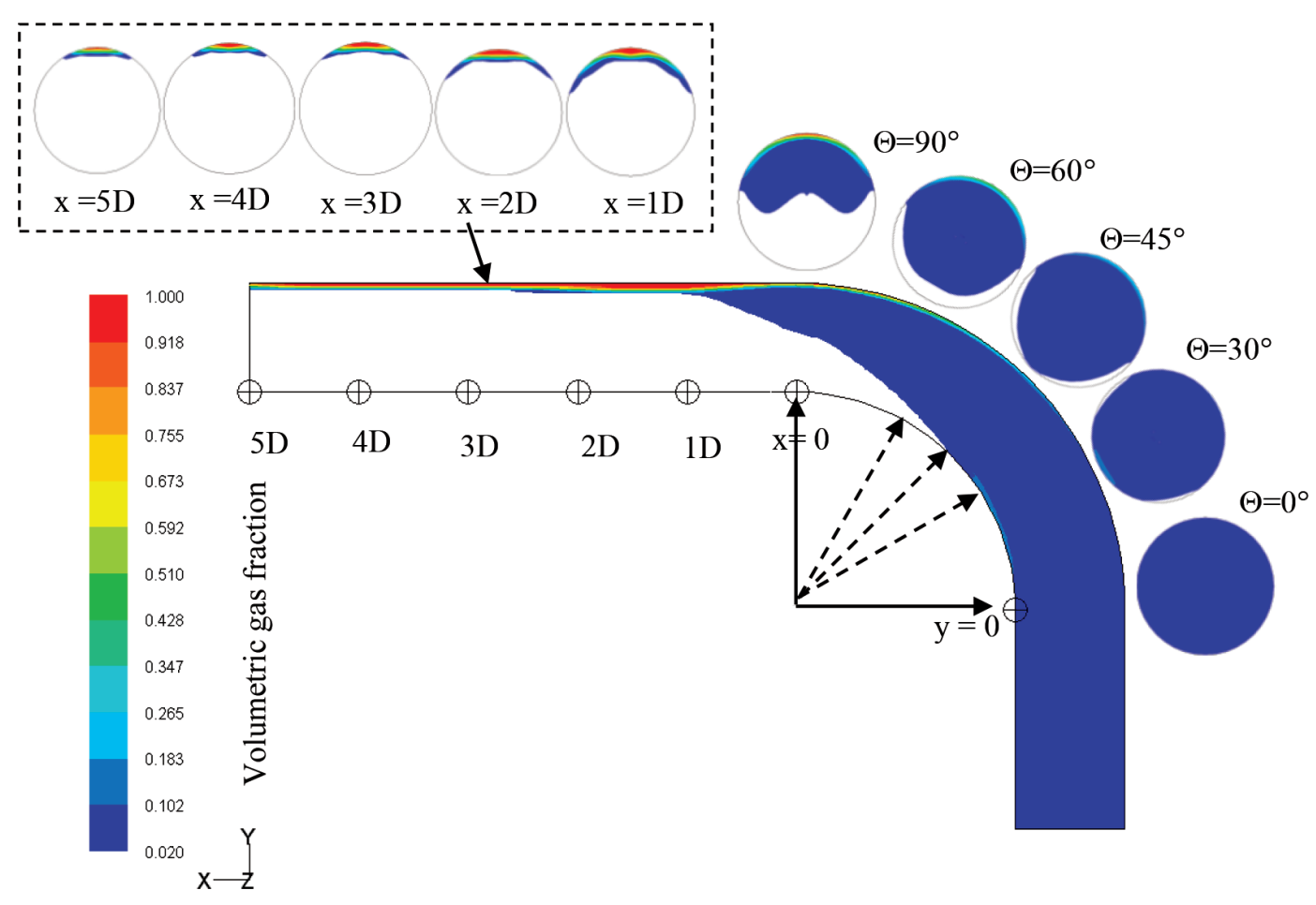

(b)

Figure 7 (a)-(b). Experimental and numerical observation of two-phase flow pattern through elbow bend at $\mathrm{Re}_{\mathrm{SL}}=31492, \beta=0.2$. 


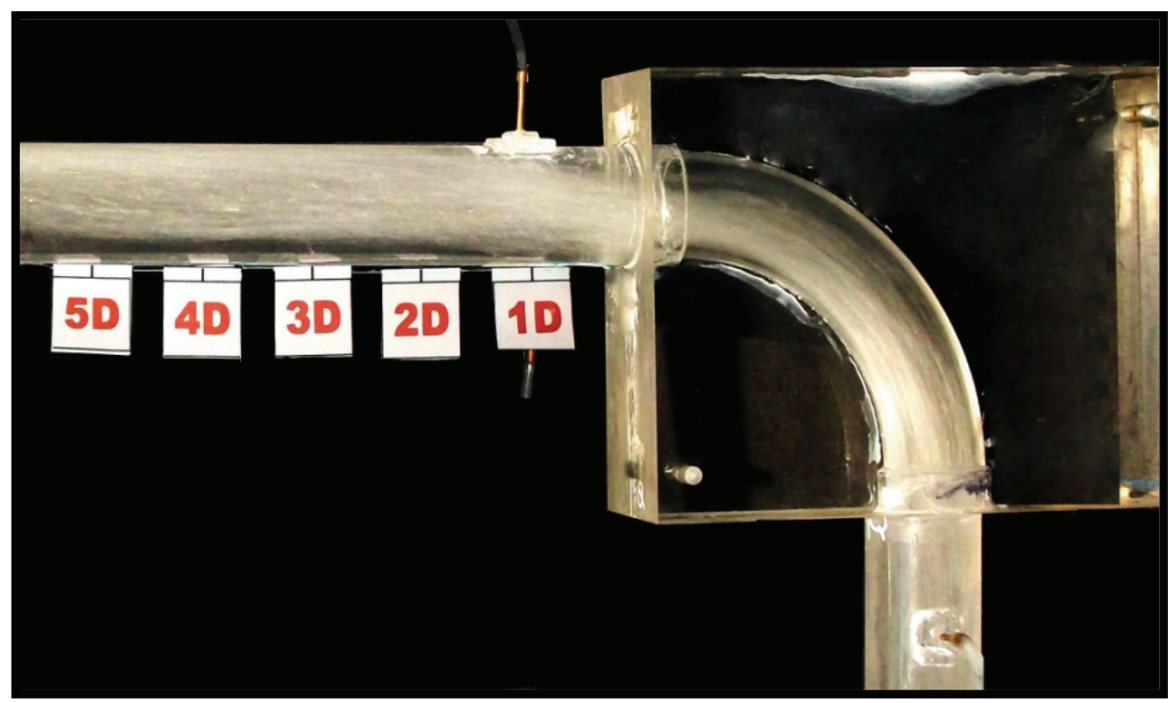

(a)

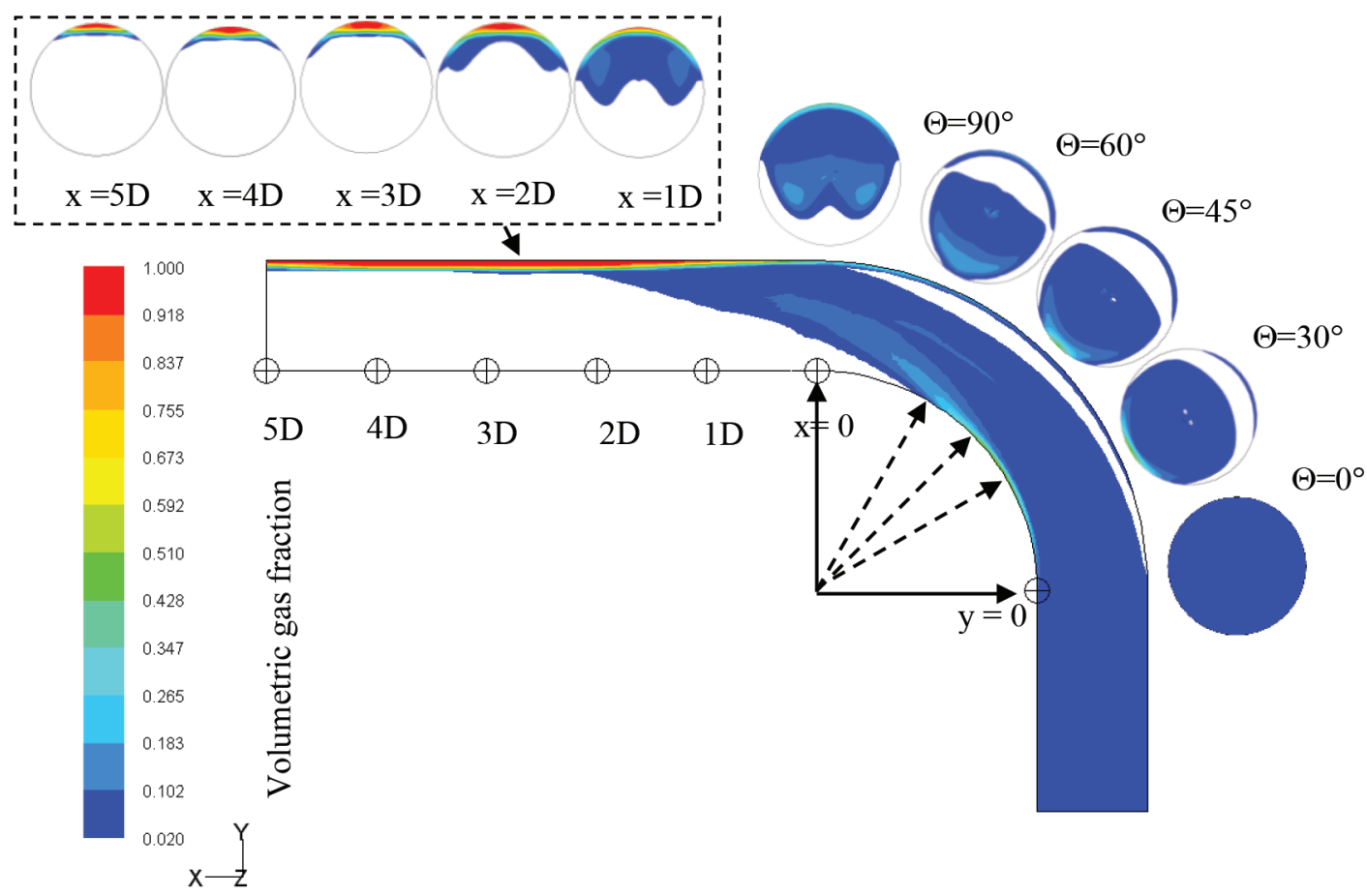

(b)

Figure 8 (a)-(b). Experimental and numerical observation of two-phase flow pattern through elbow bend at $\mathrm{Re}_{\mathrm{SL}}=40490, \beta=0.2$. 


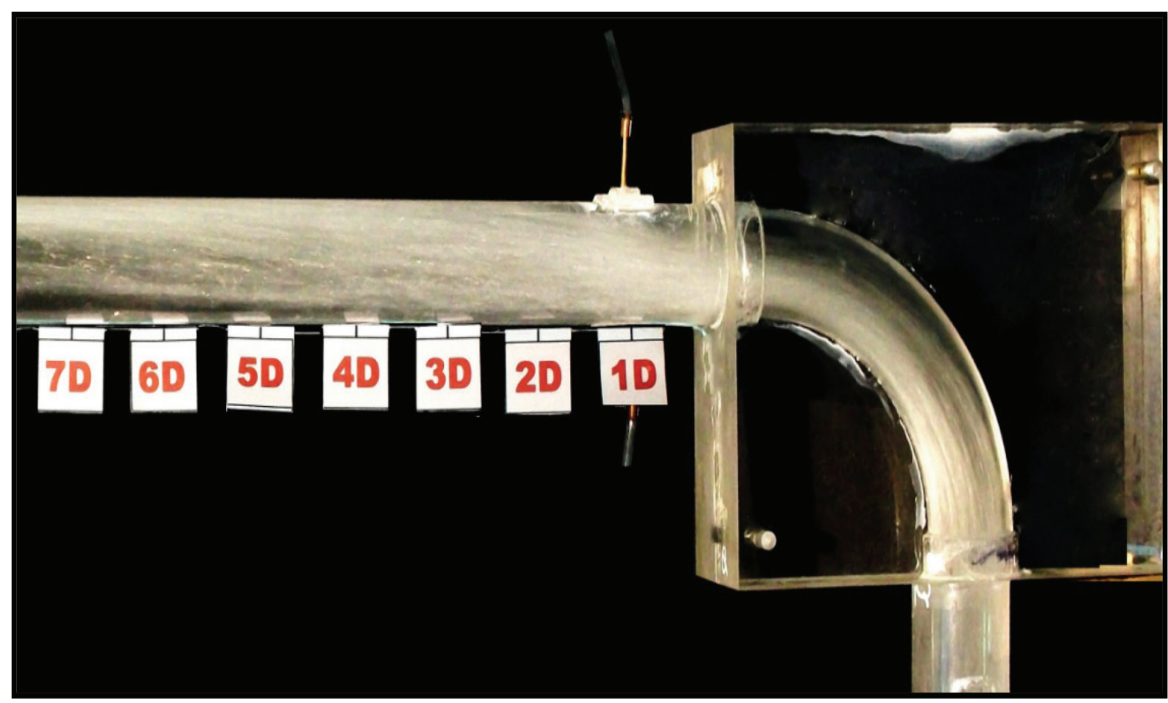

(a)

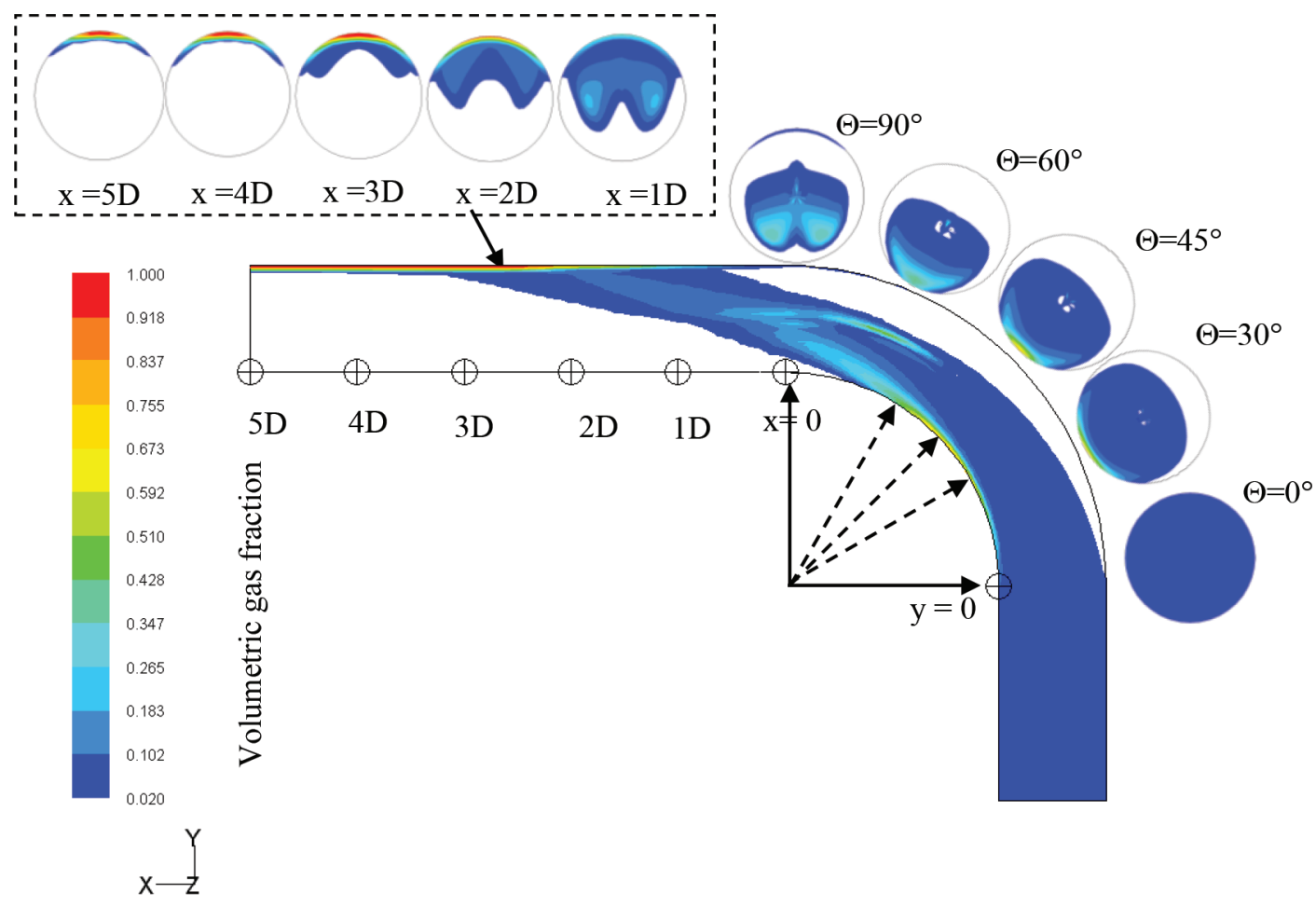

(b)

Figure $9(a-b)$. Experimental and numerical observation of two-phase flow pattern through elbow bend at $\operatorname{Re}_{\mathrm{SL}}=49488, \beta=0.2$. 
(a)

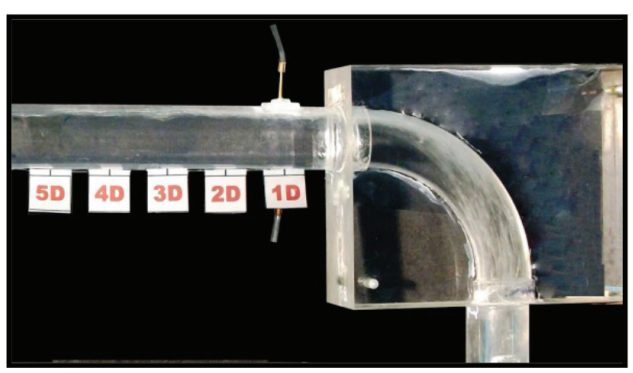

(b)

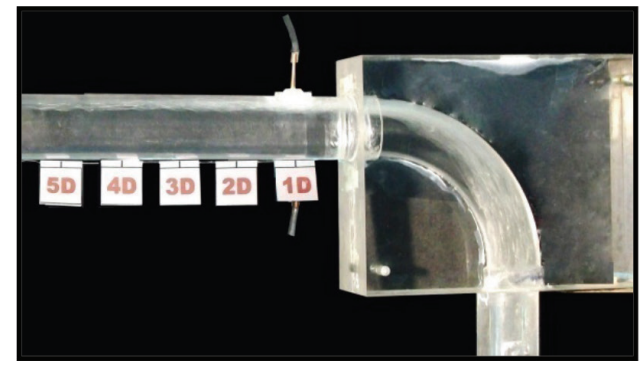

(c)

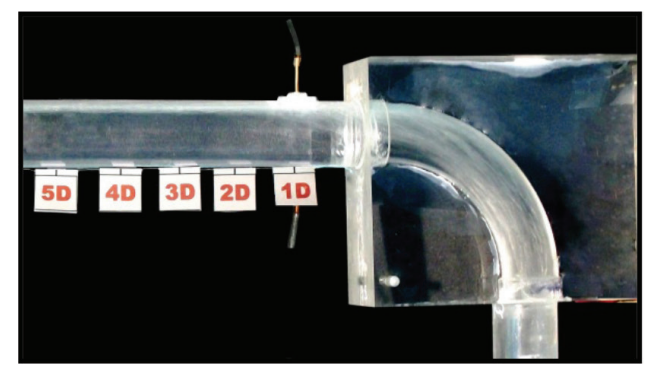

(d)

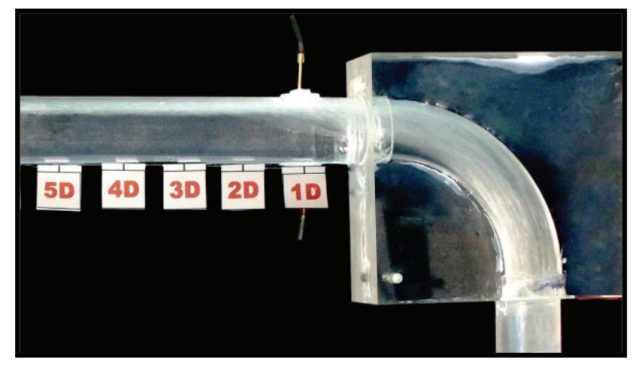

(e)

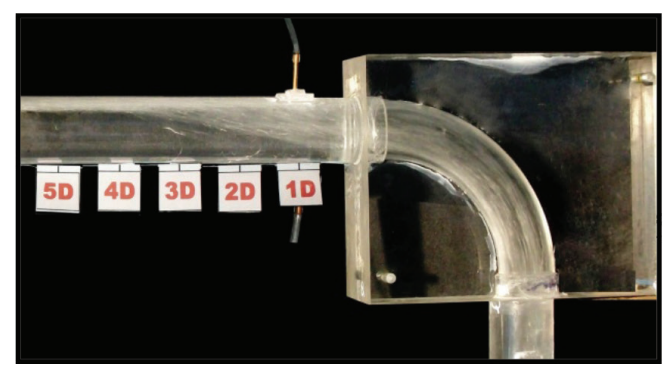

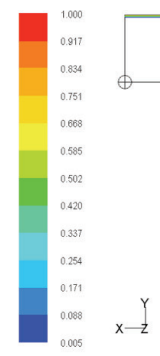
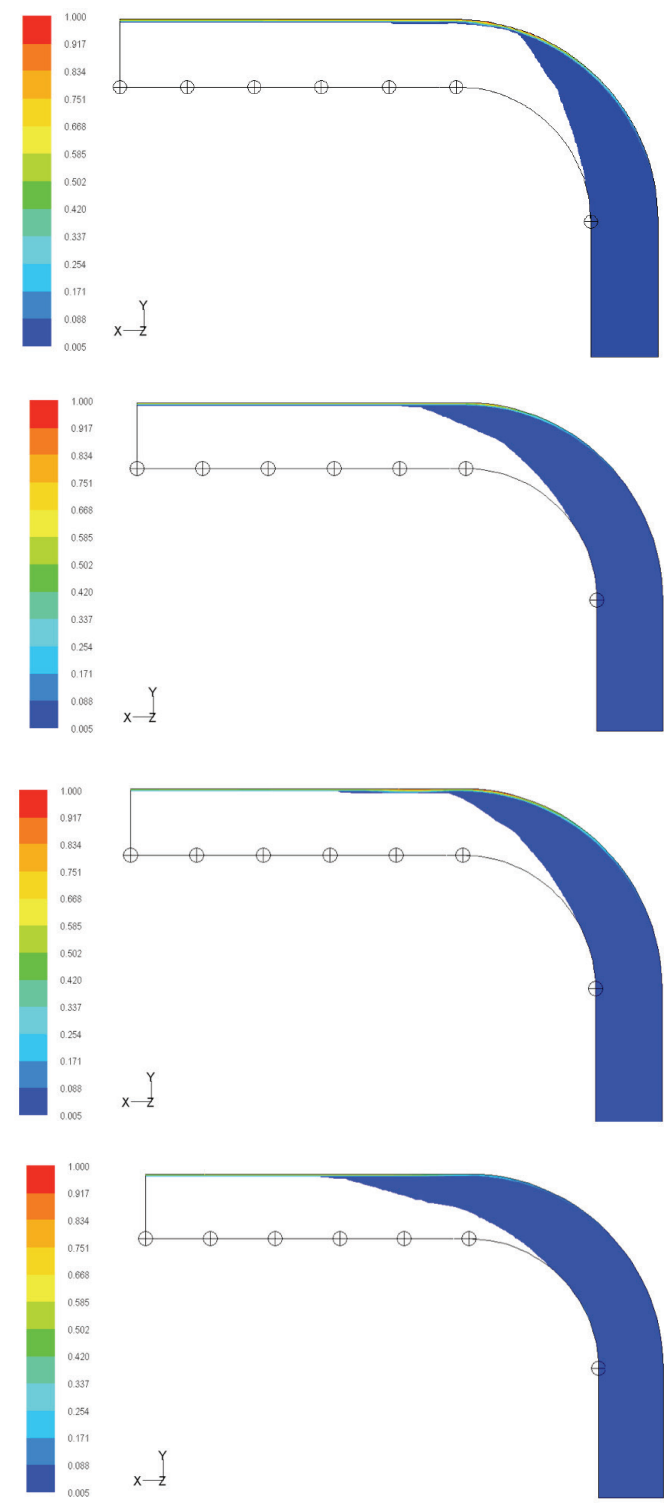

Figure 10(a)-(e). Experimental and numerical observation of two-phase flow pattern through elbow bend at: (a) $\operatorname{Re}_{\mathrm{SL}}=13497, \beta=0.11$; (b) $\operatorname{ReSL}=13497, \beta=0.15$; (c) $\operatorname{Re}_{\mathrm{SL}}=22494, \beta=0.11$; (d) $\operatorname{Re}_{\mathrm{SL}}=22494, \beta=0.15$; (e) $\operatorname{Re}_{\mathrm{SL}}=31493, \beta=0.11$. 
(f)

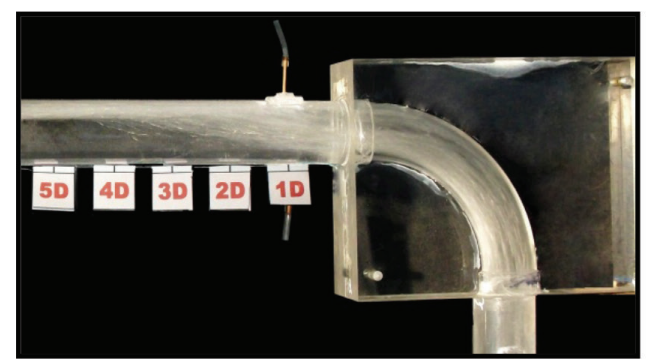

(g)

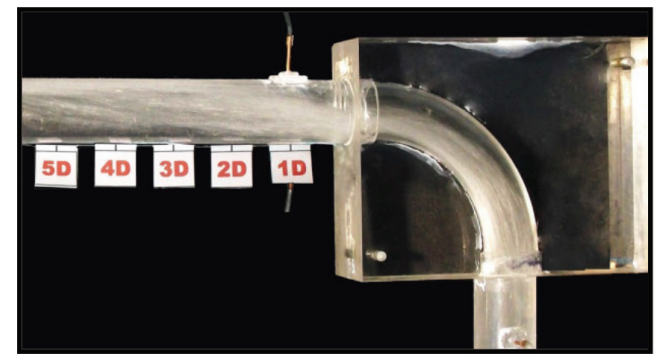

(h)

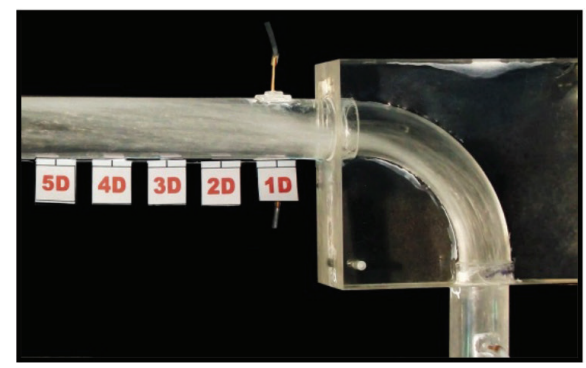

(i)

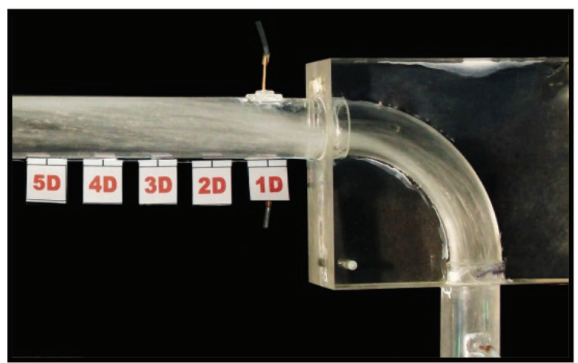

(j)

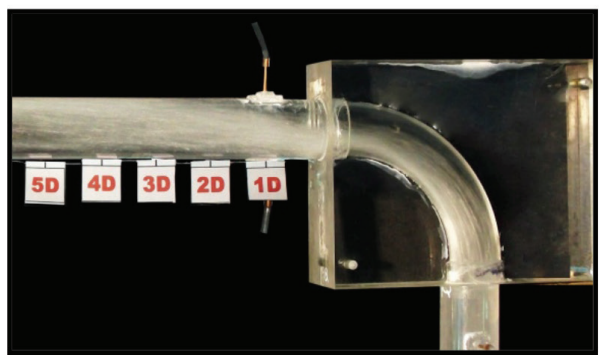

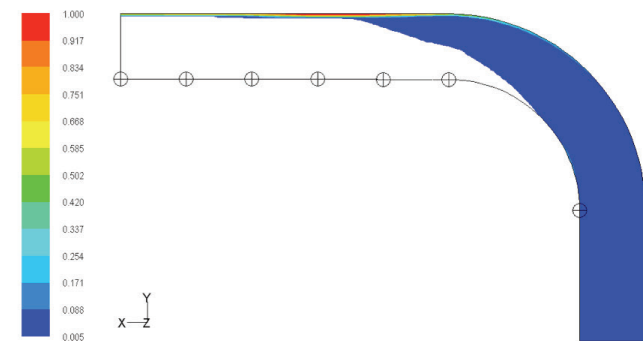
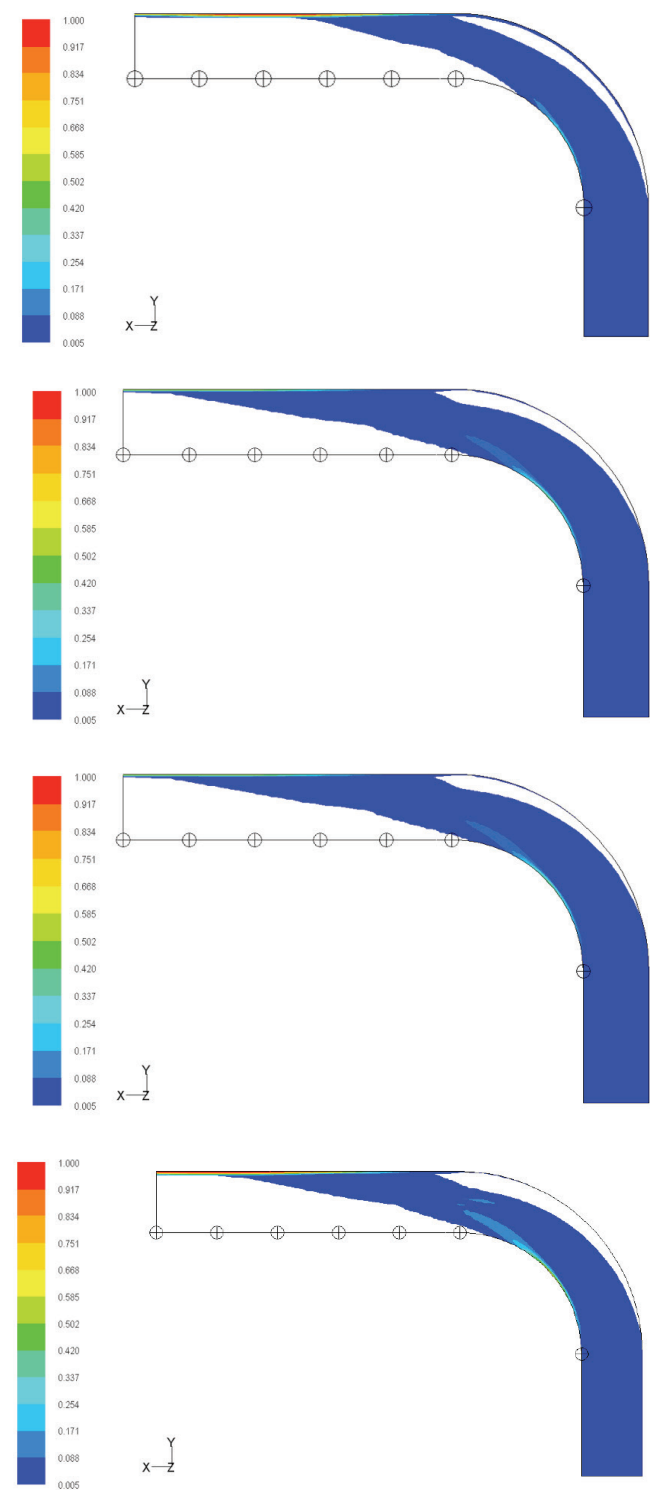

Figure 10(f)-(j). Experimental and numerical observation of two-phase flow pattern through elbow bend at: $(f) \mathrm{Re}_{\mathrm{SL}}=31492, \beta=0.15$; $(g) \mathrm{Re}_{\mathrm{SL}}=40490, \beta=0.11$; (h) $\mathrm{Re}_{\mathrm{SL}}=40490, \beta=0.15$; (i) $\operatorname{Re}_{\mathrm{SL}}=49488, \beta=0.11$; (j) $\operatorname{Re}_{\mathrm{SL}}=49488, \beta=0.15$. 
momentum impinges the outer surface and increases the surface pressure by pushing the gas phase to the lower pressure region. However no coalescence of bubbles is found at the inner surface since centrifugal force accelerates the gas bubbles without giving a chance to merge each other. From numerical results (Figures $8(b)-9(b))$, it is clearly seen that the formation of low pressure region at the inner bend creates transverse flow (or secondary flow) from elbow exit to about $1 D$. Therefore the bubbles cannot move up to the upper surface of horizontal pipe until a far distance after the elbow outlet. The bubbly flow is maintained until $5 D$ to $6 D$ after the elbow exit. Then, it starts to develop gasliquid stratified flow pattern in horizontal pipe. It can be understood that elbow bend causes liquid velocity-dependent interference in flow pattern transition from vertical to horizontal.

Observed gas-liquid two-phase phenomena through elbow bend with the variation of gas quality are described in Figures 10. For lower constant liquid velocities (Figures $10(a)-10(d))$, the increase of gas velocity enhances the gas layer formation near the elbow exit. However, the increase of gas quality promotes the interference at high liquid velocities forming a gas core in horizontal pipe (Figure $10(\mathrm{~g})-10(\mathrm{j})$ ). It postpones the formation of stratified flow pattern and creates wavy gas layer at downstream. Therefore, it can be concluded that the phase distribution after elbow bend also relates to gas quality in the mixture.

\section{CONCLUSION}

Designing a suitable elbow bend is a critical issue in separation and mixing processes. Since long elbow bends are becoming attractive in such applications, phase distribution (the flow pattern) characteristic of gas-liquid two-phase bubbly flow through a vertical to horizontal right angled $\left(90^{\circ}\right)$ long elbow bend is experimentally observed. Then numerical simulations are also performed by using CFD software, FLUENT 6.2 and qualitatively compared with experimental results. The constructed test section diameter was 0.036 $\mathrm{m}$ and the elbow curvature to diameter ratio $(R / D)$ was 2.5. Different flow conditions were created by varying superficial liquid velocity and gas quality.

The experimental and numerical results from this work were of good agreement. These results provided a clear view and understanding of phase interaction and distribution phenomena before, inside and after long elbow bend. Based on recorded observations, it could be concluded that phase distribution inside and after elbow bend mainly depended on liquid velocity. At lower liquid velocities, the gas bubbles migrate at the upper surface of bend and smoothly changed to gas layer at the elbow exit. When the liquid velocity was further increased, it occupied the outer surface, suppressed the gas phase to inner region of the bend and delayed the formation of stratified flow pattern. The increase of gas quality in a high liquid velocity also caused wavy gas layer after the elbow bend.

\section{ACKNOWLEDGEMENT}

The authors would to express their special thank to all members of Fluid Mechanic Lab, Mesin, ITS for support of their facility and great help.

\section{APPENDIX 1}

Superficial liquid velocity, $U_{S L}=\frac{Q_{L}}{A}$

Superficial gas velocity, $U_{S G}=\frac{Q_{G}}{A}$

Volumetric quality, $\beta=\frac{Q_{G}}{Q_{L}+Q_{L}}$

Superficial liquid Reynolds number,

$$
R e_{S L}=\frac{\rho_{L} U_{S L} D}{\mu_{L}}
$$

Superficial gas Reynolds number,

$$
R e_{S G}=\frac{\rho_{G} U_{S G} D}{\mu_{G}}
$$


where, the subscripts $G, L, S G, S L$ denotes gas, liquid, superficial gas, superficial liquid respectively, $U$ is superficial velocity, $Q$ is flow rate, $R e$ is Reynolds number, $D$ is pipe diameter.

\section{Date of submission: January 2013 \\ Date of acceptance: March 2014}

\section{REFERENCES}

Abdulkadir, M, Zhao, D, Sharaf et al. 2011, 'Interrogating the effect of $90^{\circ}$ bends on airsilicone oil flows using advanced instrumentation', J. Chem. Eng. Sci., vol. 66, pp. 2453-2467.

Akilli, H, Levy, EK \& Sahin B 2001, 'Gas-solid flow behavior in a horizontal pipe after a $90^{\circ}$ verticalto-horizontal elbow', J. Powder Technol, vol. 116, pp. 43-52.

Benbella S, Al-Shannag M \& Al-Anber, ZA 2009, 'Gas-liquid pressure drop in vertical internally wavy $90^{\circ}$ bend', J. Exp. Therm Fluid Sci., vol. 33, pp. 340-347.

Huseyin, H, Levy, EK \& Besir B 2004, 'Investigation of gas-solid flow structure after a $90^{\circ}$ verticalto-horizontal elbow for low conveying gas velocities', J. Adv. Powder Technol., vol. 16, 261-274.

Kim, S, Park, JH, Kojasoy, G et al. 2007, 'Geometric effects of 90-degree elbow in the development of interfacial structures in horizontal bubbly flow', J. Nucl. Eng. Des., vol. 237, pp. 2105-2113.

Liu, Y, Miwa, S, Hibiki, T et al. 2012, 'Experimental study of internal two-phase flow induced fluctuating force on a $90^{\circ}$ elbow', J. Chem. Eng. Sci., vol. 76, pp. 173-187.
Mahmoud, H, Kriaa, W, Mhiri, H, et al. 2012, 'Numerical analysis of recirculation bubble sizes of turbulent co-flowing jet', J. Eng AppL Comp Fluid, vol. 1, pp. 58-73.

Mahvash, A \& Ross A 2008, 'Two-phase flow pattern identification using continuous hidden Markov model', J. Multiphase Flow. vol. 34, pp. 303-311.

Margot, X, Hoyas, S, Gil, A, et al. 2012, 'Numerical modeling of cavitation: validation and paramtetric studies', J. Eng AppL Comp Fluid, vol. 1, pp. $15-24$.

Riverina, JR, Langre, Ed \& Pettigrew, MJ 2006, 'Fluctuating forces caused by internal two-phase flow on bends and tees', J. Sound. Vib., vol. 298, pp. 1088-1098.

Singhal, NH, Athavale, AK \& Li, M et al. 'Mathematical basis and validation of the full cavitation model', J. Fluids Eng 2002, vol. 124, pp. 1-8.

Spedding PL \& Benard E 2007, 'Gas-liquid two phase flow through a vertical $90^{\circ}$ elbow bend', J. Exp. Therm Fluid Sci., vol. 31, pp. 761-769.

Spedding PL, Benard E \& Crawford NM 2008, 'Fluid flow through a vertical to horizontal $90^{\circ}$ elbow bend III three phase flow', J. Exp. Therm Fluid Sci., vol. 32, pp. 827-843.

Yang, W \& Kuan, B 2006, 'Experimental investigation of dilute turbulent particulate flow inside a curved $90^{\circ}$ bend', J. Chem. Eng. Sci., vol. 61, pp. 359-3601.

Zhang, H, Tan, Y, Yang \& D et al. 2012, 'Numerical investigation of the location of maximum erosive wear damage in elbow: Effect of slurry velocity, bend orientation and angle of elbow', J. Powder Technol, vol. 217, pp. 467-476. 